cardiac rhabdomyoma: Implications for evaluation and follow-up. Ann Neurol

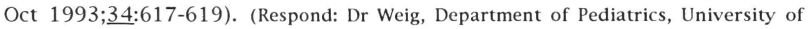
Massachusetts Medical Center, Worcester, MA 01655).

COMMENT. The authors cite one previous report of heart block secondary to erythromycin-induced CBZ toxicity in a 10-year-old boy. This child had no evidence of underlying cardiac disease. Additional cases in adults have been reported. Although CBZ cardiotoxicity is rare, an echocardiogram is recommended in patients with tuberous sclerosis treated with carbamazepine, and cardiac rhythm should be carefully monitored.

\title{
ICTAL SPECT IN LOCALIZING EPILEPTOGENESIS
}

Ictal single-photon emission computed tomography (SPECT) was used successfully in the localization of an epileptic focus in two children, ages 9 and 7 years, with intractable epilepsy reported from the University of Alabama at Birmingham Epilepsy Center. CT and initial MRIs were normal, and repeated EEG-video monitoring studies failed to localize the seizures. Resection of the abnormal areas shown by SPECT as hyperperfusion in the frontal lobes revealed a cortical dysplasia. The children had no neurological deficits and remained seizure free 1 year after surgery. (Kuzniecky R et al. Ictal singlephoton emission computed tomography demonstrates localized epileptogenesis in cortical dysplasia. Ann Neurol Oct 1993; $\underline{34: 627-631) . ~(R e s p o n d: ~ D r ~ K u z n i e c k y, ~}$ Department of Neurology, UAB Station, Birmingham, AL 35294).

COMMENT. Ictal SPECT performed exactly at the onset of a clinical seizure precisely localized the primary epileptogenic area in the cortical dysplasia and permitted a discrete resection of the focus without neurologic deficit.

\section{TEMPORAL LOBE TUMOR AND LANDAU-KLEFFNER SYNDROME}

A 7-year-old boy with a left temporal lobe tumor and Landau-Kleffner syndrome (acquired aphasia and epilepsy) who improved dramatically after surgery is reported from the New York Hospital-Cornell University Medical Center. A verbal auditory agnosia with mutism had evolved over a 3 month period after onset of refractory partial complex seizures at 5 years. EEG showed left temporal and right occipital spike and $\mathrm{S} / \mathrm{W}$ discharges. Language comprehension was absent on the Peabody Picture Vocabulary test and Token test. Following removal of a grade 1 astocytoma demonstrated on MRI, seizures stopped, language returned, and after 1 year speech and comprehension were almost normal for age. (Nass R et al. Landau-Kleffner syndrome: Temporal lobe tumor resection results in good outcome. Pediatr Neurol July/Aug 1993; $\underline{9}: 303-5)$. (Respond: Dr Nass, New York Univ Med Ctr, 400 E 34th St RR 212, New York, NY 10021). 